\title{
Bovine gangliosides and acute motor polyneuropathy
}

\author{
Albert Figueras, Francisco J Morales-Olivas, \\ Dolors Capellà, Vicente Palop, \\ Joan-Ramon Laporte
}

Unitat de Farmacologia Clínica, Institut Català de Farmacologia, Universitat Autònoma de Barcelona, CSU Vall d'Hebron,

Barcelona, Spain Albert Figueras, assistant professor

Dolors Capellà, associate professor

Joan-Ramon Laporte, professor of clinical pharmacology

\section{Departament de}

Farmacologia, Facultat de Medicina, Universitat de València, València

Francisco J Morales-Olivas, associate professor

\section{Centre de}

Farmacovigilància de la Comunitat Valenciana,

València

Vicente Palop, drug

surveillance officer

\section{Correspondence to}

Professor J R Laporte,

Servei de Farmacologia

Clinica, CSU Vall d'Hebron,

Universitat Autònoma de

Barcelona, 08035 Barcelona,

Spain.

BMF 1992;305:1330-1
Gangliosides-glycosphingolipids in mammalian cells -have a role in promoting nerve repair by increasing collateral sprouting.' Trials of exogenous gangliosides as adjuvant treatment for various neuropathies, however, either have had gross methodological deficiencies or have shown lack of clinical improvement. ${ }^{2}$ In 1989 Cronassial, a ganglioside prepared from bovine brain, was withdrawn in Germany after reports of GuillainBarré syndrome and amyotrophic lateral sclerosis in patients given it. ${ }^{3+}$

The Spanish national drug surveillance system receives reports from physicians and hospital pharmacists, covers three quarters of the general population, and has over 18000 reports in its database. We review the 17 cases of Guillain-Barre syndrome and other acute motor polyneuropathy associated with use of gangliosides reported up to 29 February 1992.

\section{Present series and results}

All 17 patients (10 women) had received fixed dose bovine gangliosides containing $\mathrm{GM}_{1}(17-25 \%)$, $\mathrm{GD}_{1 \mathrm{a}}(36-46 \%), \mathrm{GD}_{1 \mathrm{~b}}(12-18 \%)$, and $\mathrm{GT}_{1 \mathrm{~b}}(14-22 \%)$ (Nevrotal). Three had died (table). The 17 cases had been reported to six different regional centres, and in all the diagnosis had been confirmed by a neurologist. Fifteen patients had started Nevrotal within four weeks before the diagnosis. In the other two the date was unknown, though it preceded the acute motor polyneuropathy.

In eight patients the clinical indication for gangliosides either was not related to any prodrome of Guillain-Barré syndrome or acute motor polyneuropathy or had been present for too long to be interpreted as a prodrome. These cases are listed as "probable" in the table. One patient had a cold and two patients an episode of diarrhoea in the month before diagnosis. Electromyography reports were available in all eight cases. In the remaining nine cases we could not exclude the indication for using gangliosides as a prodrome. We refer to these cases as "possible."

In 14 cases the indications for using gangliosides were not among those approved in Spain (that is, diabetic and post-traumatic neuropathies). Nine patients had taken other drugs with Nevrotal (analgesic/anti-inflammatory drugs, antihypertensive agents, vitamins). Overall, 13 patients were partially or completely recovered from the complication within three months. Of the others, three died and one was continuing with gangliosides.

Albuminocytological dissociation in cerebrospinal fluid was present in seven patients. Serological tests and cerebrospinal fluid cultures for common infective agents in Guillain-Barré syndrome (Brucella, Campylobacter, Mycoplasma, herpes simplex virus, hepatitis B virus) gave negative results in all nine cases for which this information was available. Lyme disease may cause similar neuropathies." Antibodies to Borrelia were sought unsuccessfully in three patients.

\section{Comment}

Assessing a causal relation between exposure to bovine gangliosides and acute motor polyneuropathy is problematical. Firstly, the symptoms of these conditions are heterogeneous and the time courses unknown. Hence it may be difficult to establish whether the drug was administered before the onset of neurological disturbances or if it was prescribed to treat early symptoms. Secondly, antecedent infections by various agents are reportedly associated with Guillain-Barré syndrome. However, the agents which might be involved and how infection triggers the disease are unknown. We know even less about the aetiology of acute motor polyneuropathy. It is difficult to support the lack of a causal relation in some cases solely on the basis of an antecedent of the common cold, flu, or diarrhoea several days before the onset of symptoms.

A historical cohort study aimed at determining the

Clinical features of 17 cases of acute motor polyneuropathy associated with exposure to gangliosides reported to Spanish drug surveillance system

\begin{tabular}{|c|c|c|c|c|c|c|c|}
\hline Case No & Sex & $\begin{array}{c}\text { Age } \\
\text { (years) }\end{array}$ & Indication for gangliosides & $\begin{array}{l}\text { Time from } \\
\text { start of } \\
\text { treatment to } \\
\text { clinical } \\
\text { diagnosis } \\
\text { (weeks) }\end{array}$ & $\begin{array}{c}\text { Clinical diagnosis recorded on } \\
\text { yellow card }\end{array}$ & Findings on electromyography & $\begin{array}{l}\text { Recovery period } \\
\text { (weeks) }\end{array}$ \\
\hline \multicolumn{8}{|c|}{ "Probable" cases } \\
\hline 1 & $\mathrm{M}$ & 68 & Carpal tunnel syndrome & 1 & Polyradiculoneuritis & Acute polyradiculoneuritis & $>12$ \\
\hline 2 & $\mathrm{~F}$ & 50 & Lumbago for one year & 2 & Guillain-Barré syndrome & $\begin{array}{l}\text { Compatible with Guillain-Barré } \\
\text { syndrome }\end{array}$ & $>24$ \\
\hline 3 & $\mathrm{~F}$ & 59 & Chronic bone pain & $<4$ & $\begin{array}{l}\text { Strength loss, atypical Guillain- } \\
\text { Barré syndrome }\end{array}$ & $\begin{array}{l}\text { Axonal polyradiculoneuritis without } \\
\text { demyelination }\end{array}$ & 12 \\
\hline 4 & $\mathrm{~F}$ & 68 & Ankle pain for seven months & Unknown & Guillain-Barré syndrome & Acute polyradiculoneuritis & Died \\
\hline 5 & $\mathrm{~F}$ & 60 & Osteoarthritis & $<1$ & $\begin{array}{l}\text { Severe-tetraparesis, respiratory } \\
\text { failure }\end{array}$ & $\begin{array}{l}\text { Compatible with Guillain-Barre } \\
\text { syndrome }\end{array}$ & Died \\
\hline 6 & M & 70 & Osteoarthritis in knee & 2 & Guillain-Barré syndrome & Demyelinating polyradiculoneuritis & 5 \\
\hline 7 & $\mathrm{~F}$ & 44 & Self limiting pain in spine and legs & 3 & Guillain-Barré syndrome & Demyelinating polyradiculoneuritis & $>20$ \\
\hline 8 & $\mathrm{~F}$ & 41 & Arm pain for two months & 2 & Polyradiculoneuritis & Demyelinating motor polyneuropathy & $<8$ \\
\hline \multicolumn{8}{|c|}{ "Possible" cases } \\
\hline 9 & M & 38 & Pain in right thigh & $<4$ & Toxic polyradiculoneuritis & Acute polyradiculoneuritis & $>24$ \\
\hline 10 & M & 35 & Neuralgia, rhinitis, vertigo & 2 & Guillain-Barré syndrome & $\begin{array}{l}\text { Compatible with Guillain-Barre } \\
\text { syndrome }\end{array}$ & 3 \\
\hline 11 & $\mathrm{~F}$ & 64 & Left sciatic pain & $<2$ & $\begin{array}{l}\text { Flaccid-tetraparesis, areflexia, } \\
\text { dyspnoea }\end{array}$ & Diffuse polyneuropathy & Died \\
\hline 12 & $\mathrm{~F}$ & 19 & Post-traumatic strength loss in legs & 4 & Guillain-Barré syndrome & No data & $\begin{array}{l}\text { Still receiving } \\
\text { gangliosides; } \\
\text { acute motor } \\
\text { polyneuropathy } \\
\text { persisting }\end{array}$ \\
\hline 13 & $M$ & 61 & Strength loss & Unknown & $\begin{array}{l}\text { Guillain-Barré syndrome, limb } \\
\text { weakness increased }\end{array}$ & No data & $?$ \\
\hline 14 & M & 47 & $\begin{array}{l}\text { Pain in ankle and proximal limb, paraesthesia, strength } \\
\text { loss }\end{array}$ & $2-3$ & Guillain-Barré syndrome & Motor polyradiculoneuritis & $>16$ \\
\hline 15 & M & 60 & Arm pain probably related to post-traumatic neuritis & 3 & Mixed polyneuropathy & $\begin{array}{l}\text { Demyelinating sensory motor } \\
\text { polyneuropathy }\end{array}$ & $?$ \\
\hline 16 & $\mathrm{~F}$ & 63 & Right intercostal neuralgia & $<4$ & Guillain-Barré syndrome & Slow conduction, amplitude reduction & $>12$ \\
\hline 17 & $\mathrm{~F}$ & 44 & Hand pain & 1 & Polyradiculoneuritis & Demyelinating polyneuropathy & $>4$ \\
\hline
\end{tabular}


safety of bovine gangliosides was carried out in Ferrara, Italy. No case of Guillain-Barré syndrome was found, but the sample was small (18945 person years) given the incidence of the syndrome $(0.6$ to $1.9 / 100000$ population yearly). ${ }^{5}$

Studying the aetiology of conditions whose pathophysiology and clinical course are poorly understood may be difficult and controversial. Formal epidemiological studies in this setting, however, can be justified only if the efficacy of the suspected causal drug is clearly delineated. This is not the case with gangliosides, and hence the Spanish National Commission of Pharmacovigilance has proposed their withdrawal.
We thank Drs A Arias and M M Lainez (Granada); Drs J R Castillo and J Torelló (Sevilla); Drs J M Rodriguez-Sasiain and I Ayani (Bilbao); Dr E J Sanz (Sta Cruz de Tenerife); and Drs F Tato and M Martí (Santiago de Compostela) from the regional centres of Andalucia, Euskadi, Canarias, and Galicia.

1 The regenerative nervous system. Lancet 1985; $11137-8$.

2 Bradley WG. Critical review of gangliosides and thyrotropin-releasing hormone in peripheral neuromuscular diseases. Muscle Nerve 1990;13:833-42.

3 Schönhöfer PS. Guillain-Barre syndrome and parenteral gangliosides. Lancet 1991;338:757.

4 Latov N, Koski C, Walicke P. Guillain-Barté syndrome and parenteral gangliosides. Lancet 1991;338:757.

5 Ropper AH. The Guillain-Barre syndrome. N Engl F Med 1992;326:1130-6.

(Accepted 1 September 1992)

\title{
The incidences of lung cancer and breast cancer in women in Glasgow
}

\author{
Charles R Gillis, David J Hole, \\ Douglas W Lamont, Ann C Graham, \\ Stella Ramage
}

West of Scotland Cancer Surveillance Unit, Ruchill Hospital, Glasgow G20 9NB

Charles R Gillis, consultant epidemiologist

David J Hole, principal epidemiologist

Douglas W Lamont, senior statistician

Ann C Graham, cancer records officer

Stella Ramage, programmer

Correspondence to: $\mathrm{Dr}$ Gillis.

$B M \mp 1992 ; 305: 1331$

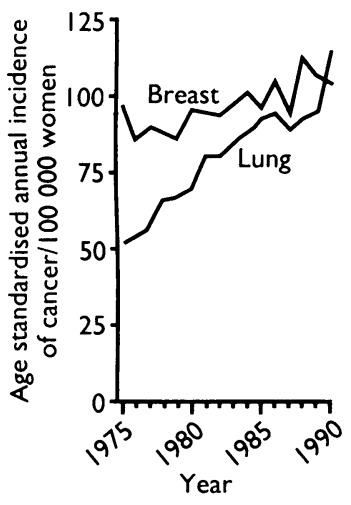

Incidence of breast and lung cancer in women in the City of Glasgow, 1975-90
Death rates from lung cancer have been increasing steadily in women since the 1950 s. $^{1}$ We report changes since 1975 in the incidence of breast and lung cancer in women in Glasgow, an area where the incidence of lung cancer is particularly high. ${ }^{2}$

\section{Methods and results}

We studied all incident cases of lung cancer (ICD (ninth revision) code 162) and breast cancer (ICD (ninth revision) code 174) that occurred during $1975-90$ in women resident in the City of Glasgow local government district (population in 1990, 689 000). Incidence rates were standardised for age against the population for 1981. Population data were obtained from the annual reports of the registrar general for Scotland.

The age standardised incidence of lung cancer increased from $52 / 100000$ in 1975 to $115 / 100000$ in 1990. That of breast cancer increased slightly from $97 / 100000$ in 1975 to $105 / 100000$ in 1990 (figure). Women aged 55-64 were the youngest group in whom the incidence of lung cancer increased. The steepest increase occurred in women aged 65-74: in these women the rate for 1990 was 3.6 times that for 1975 $(p<0.001)$. Women born during 1915-29 experienced the highest rates of lung cancer. The incidence for a given age progressively decreased for women born after 1930. The median age at diagnosis of lung cancer was 62 for women born during 1915-29.

Ratios of mortality to incidence for breast and lung cancer in Glasgow changed little between 1975 and 1990. Registrations based solely on death certification data showed a similar pattern for both sites over the period.

\section{Comment}

The increase in the incidence of lung cancer is unlikely to be due to bias in the registration of cancer in Glasgow. It is also unlikely to be an artefact of lung cancers being registered without histological verifi- cation. A case-control study carried out in western Scotland during 1976-81 compared exposure to cigarette smoke for patients with lung cancer with and without histological verification and showed no difference in the relative risk. ${ }^{2}$

Our results are consistent with the considerable time lag between exposure to risk and onset of lung cancer. Smoking became common among men before the first world war and among women some 40 years later.' The first effects of this on rates of lung cancer were observed in men from the late 1940 s onwards, ${ }^{1}$ consistent with a latent period for lung cancer related to smoking of roughly 40 years. ${ }^{3}$ Comparable mortality from lung cancer in women was seen from 1980 onwards. ${ }^{2}$ The highest age specific rates of lung cancer in Glasgow were found in women born during 1915-29. On average, these women started smoking at the age of 20 and developed lung cancer at 62 . A case-control study of smoking and lung cancer in Glasgow and western Scotland ${ }^{2}$ and a study of a cohort of the general population of Renfrew and Paisley ${ }^{4}$ suggest that these women were more likely to have taken up cigarette smoking, were less likely to have given up, smoked more per day, and started smoking earlier than women born before 1915 . Women born after 1930 had similar smoking habits to those born in 1915-29 except that a higher proportion smoked lower tar cigarettes.

The risk of lung cancer is now set for many women. Only a reduction in cigarette smoking will prevent young women experiencing the premature morbidity of their elders, but they are unlikely to achieve this without help. More effective methods of preventing and stopping smoking are required. Forty years after Doll and Hill's seminal paper linking lung cancer to cigarette smoking ${ }^{5}$ this cancer, for which prospects for long term prevention are good, has paradoxically become more common than breast cancer, whose causes are less well understood and for which prospects for primary prevention seem limited.

We thank Tracy Marr, Eileen Dott, Ena Macpherson, Patricia Williams, Rena Mauchin, and Ann Clark for their clerical, technical, and secretarial help.

\footnotetext{
1 Royal College of Physicians of London. Smoking and health now. London: Pitman, 1971.

2 Gillis CR, Hole DJ, Boyle P. Cigarette smoking and male lung cancer in an area of very high incidence. I. Report of a case-control study in the west of Scotland. I Epidemiol Community Health 1988;42:38-43.

3 Schottenfeld D, Fraumeni JF. Cancer epidemiology and prevention. Philadelphia: W B Saunders, 1982.

4 Gillis CR, Hole DJ, Hawthorne VM. Cigarette smoking and male lung cancer in an area of very high incidence. II. Report of a general population cohort study in the west of Scotland. I Epidemiol Community Health 1988;42:44-8.

5 Doll R, Hill AB. A study of the aetiology of carcinoma of the lung. $B M 7$ 1952;ii:1271-86.
}

(Accepted 30 September 1992) 